$\xi_{p}=1$

\title{
Implementation of a functional supportive programme for survivors of cerebro-vascular accidents and their caregivers at home
}

\author{
Suama W Kuugongelwa *, Louis F Small \\ Institution: University of Namibia, Private Bag13301; Windhoek: Namibia \\ *Corresponding author E-mail: skuugongelwa@unam.na
}

\begin{abstract}
A cerebro-vascular accident is a devastating experience and those who survive the initial incident often suffer from a variety of physical disabilities. These disabilities frequently result in an adult becoming incapable of, or being limited in, the provision of ongoing effective self-care. In anticipation of improving such situations the researcher developed a supportive-educative programme to be conducted in a home-based setting. This programme formed part of the main study and was implemented over four days. The researcher considered these educative sessions to be an ideal approach for implementing the programme, because adjusting, stabilising and coping can only be facilitated and put into practice through interactive participation. Eight survivors of cerebro-vascular accidents and their caregivers, all of whom had participated in the main study, were selected for the training sessions. During these sessions, the purpose, objectives and content of the programme were presented and discussed. Following the sessions, the participants were encouraged to apply what they had learnt from the training. After two months the researcher and the participants came together to conduct an evaluation of the programme.
\end{abstract}

Keywords: Implementation; Applications; Supportive Programme.

\section{Introduction}

This article is extracted from the author's original study "An educational programme to support survivors of cerebro-vascular accident and their caregivers at home in Oshana region of Namibia". The final outcome of this study was the development of a support programme. This article describes the implementation of the support programme.

Implementation refers to the process of putting into practice an idea, an educational programme or a set of activities and structures for people who are then expected to change as a result (Peu, 2008). Hence, the researcher was persuaded that if the survivors of cerebro-vascular accidents and their caregivers were to implement the support programme it would enable them to cope with the challenges experienced in their daily activities at home.

\section{Purpose}

The purpose of the implementation was to offer knowledge and empower the survivors and their caregivers to be self-reliant by enhancing their self-care and social skills appropriately whilst attempting to adjust to an altered lifestyle.

\section{Objectives}

The objectives of the programme were to
- Implement and facilitate the educational programme for the survivors of cerebro-vascular accident and their caregivers over a predetermined period of four days

- Conduct supportive-educative sessions to determine survivors' and caregivers' ability to function optimally at home

- Ensure active participation by participants for the duration of the educational programme.

\section{The programme implementation process}

The supportive educational programme was implemented over a period of four days and included learning activities and functional assessment content.

\subsection{Schedule}

The implementation of the educational programme took place according to a specific schedule which provided for the various sessions to take place. Participation in the programme was voluntary and written consent was given by each participant before she or he started attending the sessions. The participants received a programme schedule and a handout consisting of course material. A schedule for implementing the educational programme was developed and the sessions are shown in Figure 1. 


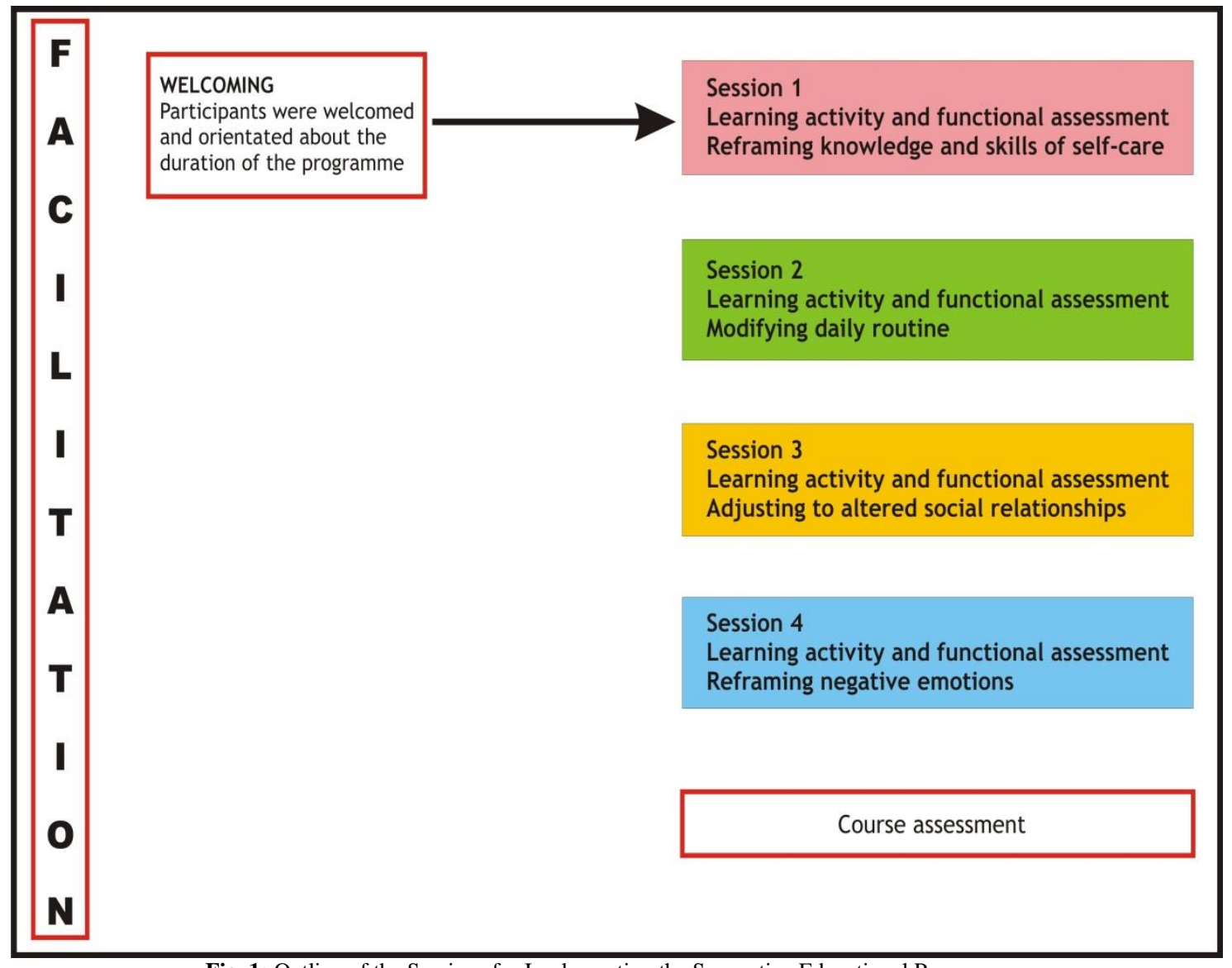

Fig. 1: Outline of the Sessions for Implementing the Supportive Educational Programme.

The implementation process took four hours. This included establishing rapport, orientating participants to the programme and introducing them to concepts of optimal functioning. Time was also allowed for queries, travel to the participants' homes and unexpected events. The programme was implemented over four days. The researcher/facilitator planned to visit two survivors of a cerebro-vascular accident and their caregivers every day, and the entire content of the programme was covered on that particular day.

Eight survivors of a cerebro-vascular accident and their caregivers were selected for the programme. These participants had also participated in the main study. For implementing the programme, the researcher opted to conduct individualised home sessions, as the home environment is the area or space where the survivors of cerebro-vascular accident and their caregivers carry out all the activities of daily life. This environment therefore creates unique and individual focus areas, which it would not have been possible to address in a more formalised group-focused workshop. The researcher accordingly maintained that conducting this programme in the home would be more conducive to effective learning. These home visits comprised a four-hour session with each of the patients and their respective caregivers. In total, thirty-two hours were spent on implementing the programme.

\subsection{Facilitation}

Facilitation is considered an essential component of learning through practice and has drawn the emphasis away from didacticism (Banning, 2005). The focus of programme implementation was on active participation and dual interaction and facilitation was an important activity throughout the implementation stage. However, the role of the researcher as facilitator in this exercise was of the utmost importance and cannot be ignored, as her role in this respect was to keep the survivors and their caregivers on track, and help them to focus on their tasks during the various phases of content presentation. The more involved the client is in the process of caring for him or herself, the more receptive she or he is likely to be to new learning (Armentrout, 2005).

Furthermore, the facilitator's role is to provide a clear link between what is important (objectives), what will be learnt (outcomes) and how it will be learnt (teaching). The facilitator should have knowledge, insight and understanding of the concept concerned in order to help to facilitate, in this case, optimal functioning in participants. This description applied perfectly to the facilitator of this educational programme in view of the fact that participants' participation had to be active in order to acquire the necessary self-care skills (Young et al., 2007)

\section{Sessions and learning content}

The learning content comprised the following information:

\begin{tabular}{|l|}
\hline Session 1 \\
Learning content: \\
- Reframing knowledge and skills of self-care \\
- Improve knowledge and skills of self-care \\
\hline
\end{tabular}

Session 2

Learning content:

- Modifying daily routine

- Dealing with role change as a marital partner, parent and financial supporter

\begin{tabular}{l} 
Session 3 \\
Learning content: \\
- $\quad$ Adjusting to altered social relationships \\
- $\quad$ Reintroducing leisure activities \\
- Minimising caregiver's lifestyle disruption \\
- Maintaining social support \\
- $\quad$ Improintaining regular follow-ups to visit health facility \\
\hline
\end{tabular}


Session 4

Learning content:

- Reframing negative emotions

- Dealing with emotional changes that is, anger, worry and guilt

Fig. 2: The Learning Content.

\subsection{Session 1: reframing knowledge and skills of self- care}

Session 1 provides knowledge and skills that will enable the survivors of a cerebro-vascular accident and their caregivers to excel in their capacity to take care of themselves.

\subsubsection{Aims and functional outcomes of session 1}

The aim of this session is for the survivors of a cerebro-vascular accident and their caregivers to acquire knowledge and explore skills that will enable them to overcome their self-care limitations. The functional outcome for this session is thus reframed as knowledge and skills of self-care.

\subsubsection{Content}

The content includes the concepts of self-care: dressing or grooming, transfer, mobility and promotion of normal sleep patterns

- Guide the caregiver to place all the articles needed for selfcare in terms of dressing near to the survivor.

- Provide assistance whenever needed for transfers such as from bed to wheelchair.

- Encourage the survivor to exercise so as to promote mobility.

- Provide encouragement and positive reinforcement for minor improvements in activity level.

- Keep a regular sleep schedule.

- Go to bed and wake up at the same time every day, even on weekends.

- Nap early in the afternoon. Napping too late in the day may disrupt night-time sleep.

\subsubsection{Expected learning outcomes}

After this session the participants will be able to

- Carry out dressing activities within limitations

- Carry out transfers with minimal assistance

- Use alternative measures available for improving mobility

- Promote normal sleep patterns.

\subsection{Session 2: modifying the daily routine}

\subsubsection{Aims and functional outcomes}

The aim of this session is for the survivors of a cerebro-vascular accident and their caregivers to explore the skills that will enable them to deal with their role change as marital partner, parent and financial supporter. The functional outcome is the modification of their daily routine to enable survivors and caregivers to facilitate optimal functioning at home.

\subsubsection{Content}

The content includes the concepts involved in dealing with role changes as a marital partner, parent and financial supporter.

DEALING WITH ROLE CHANGE AS A MARITAL PARTNER

- The quality of the relationship before the accident is the best indicator of how well both partners will adjust afterwards.

- The closeness that a couple shares before a stroke will affect how their relationship evolves after the cerebro-vascular accident.

- It is important to remember that marital satisfaction, both giving and receiving, can be accomplished in many ways.
- Whatever is comfortable and acceptable between you and your partner is normal in the marital relationship.

- Be assured that it takes time, but with time many couples discover new ways of caring for and relating to each other (Lee-Hood Ahmad et al., 2009).

\section{DEALING WITH ROLE CHANGE AS A PARENT}

- The ability to adapt and adjust family roles and responsibilities is what ensures that each member's needs are met.

- In a functional family, other family members are able to adapt and change their roles and expectations so they can assume the responsibilities that belonged to the disabled member. This shifting and sharing of responsibilities enables necessary family processes to continue (Cookfair, 2004).

DEALING WITH ROLE CHANGES AS A FINANCIAL SUP-

\section{PORTER}

- If the survivor of a cerebro-vascular accident's condition permits, he or she should be encouraged to be evaluated for the potential of returning to work.

- The survivor who was previously employed should be referred for vocational counselling (if it exists) for assistance in returning to work.

- If the survivor is considering a return to work but he/she has psychosocial barriers (e.g. motivational, emotional and psychological concerns) she or he should be referred for supportive services such as psychological services (Duncan et al., 2005).

\subsubsection{Expected learning outcomes}

After this session the participants should be able to deal with role changes as

- Marital partner

- Parent

- Financial supporter.

\subsection{Session 3: adjusting to altered social relationships}

\subsubsection{Aims and functional outcomes}

The aims of this session are for survivors and caregivers to explore the skills that will enable them to reintroduce leisure activities, minimise disruption of the caregiver's lifestyle, maintain social support, make regular follow-up visits to the health facility and improve communication.

\subsubsection{Content}

The content includes the concepts involved in the reintroduction of leisure activities, minimising lifestyle disruption, maintaining social support, making regular follow-up visits to a health facility and improving communication.

\section{REINTRODUCTION OF LEISURE ACTIVITIES}

- Reintroduce leisure activities to one's life. Activities might include playing music, participating in plays, gardening, going to church and so on.

- You do not have to stop doing the things you enjoyed before the cerebro-vascular accident. Favourite leisure activities can be adapted to almost every situation.

- Involvement in pleasurable pursuits can help shift attention from your disability to your abilities and can enhance your self-esteem (McEwen, 2004).

\section{MINIMISE DISRUPTION OF CAREGIVER'S LIFESTYLE}

- If you, as the caregiver, can give yourself a break from caregiving, you will be helping both yourself and the survivor of a cerebro-vascular accident.

- Set aside time for yourself. This could be as simple as a relaxing bath, time to read a book, or going out with friends. 
- Don't be shy about enlisting the occasional help of other relatives, friends, neighbours or community volunteers who may be able to give you a break for a few hours each week (Hartz \& Splain, 2005).

- Successful caregiving should not be the sole responsibility of one person. Caring for a family member can be a mutually rewarding and satisfying family experience.

- In addition, a paid helper may be available to offer you time away from your hard work as a caregiver.

MAINTAIN SOCIAL SUPPORT

- An important factor within social support is the re-entry into the community and the redevelopment of socialising skills.

- The survivor of a cerebro-vascular accident is encouraged not to stop doing the things he/she has enjoyed before the accident.

- Leisure activities can lead to social opportunities: community centres, church groups and other organisations that offer recreation programmes (Lee-Hood Ahmad et al., 2009).

MAINTAIN REGULAR FOLLOW-UP VISITS TO A HEALTH

FACILITY

The survivors of a cerebro-vascular accident and their caregivers are advised and encouraged to maintain regular follow-up visits because, at health facilities

- Health professionals, survivors of cerebro-vascular accident and the family can discuss issues related to the survivors

- Survivors and caregivers or family members are given an opportunity to ask questions. These questions should be professionally answered (Kozier, Erb, Berman \& Snyder, 2004).

- The survivor's vital signs are checked and recorded in his/her record; and any abnormalities should be reported to the physician (Ignatavicius, 2003).

\section{IMPROVE COMMUNICATION}

- Communication is defined as the giving and receiving of information or messages (Benner \& Pratt, 2006). This exchange of information involves a complex process, which results in varying degrees of clarity.

- When communication is clear, the receiver understands the message that has been given, and communication is said to be functional. When the receiver does not understand the message that has been given, communication is described as dysfunctional (Hall \& Weaver, 2004).

- Speak directly to the survivor of a cerebro-vascular accident. Speaking directly to him/her decreases the chances of misinterpreting the spoken word.

- Use simple one-word commands and gestures. Uncomplicated communication is easier to comprehend.

- A relaxed and supportive atmosphere facilitates communication between caregiver and the survivor and this facilitates understanding (Simmons-Mackie \& Damico, 2004).

\subsubsection{Expected learning outcomes}

After this session the participants should be able to

- Reintroduce leisure activities

- Minimise disruption of caregiver's lifestyle

- Maintain social support

- Maintain regular follow-up visits to the health facility

- Improve communication.

\subsection{Session 4: reframing negative emotions}

\subsubsection{Aims and functional outcomes}

The aims for this session are for the survivors of cerebro-vascular accident and their caregivers to explore the knowledge and skills that will enable them to deal with anger, worry and guilt.
The content includes the concepts involved in dealing with emotions of anger, worry and guilt.

\section{DEALING WITH NEGATIVE EMOTIONS}

- Shortly after the cerebro-vascular accident, survivors and families begin to comprehend their personal losses and go through a grieving process. Recognising the stages of grief can help you cope better with the emotional stages that accompany grief. Caregivers and families can gain insight into the grieving process as well, so they can better understand survivor's thoughts, feelings and actions (Lee-Hood Ahmad et al., 2008).

- You may not go through every stage. One stage does not stop abruptly so that the next can begin. Rather, grieving is a gradual healing process that takes time and work. Each person moves back and forth between the stages at his/her own rate.

\section{DEALING WITH ANGER}

- Feelings of anger are common in survivors following their cerebro-vascular accident. These feelings may be expressed verbally or physically, or by withdrawing from the family. Others may express their anger by being overly critical of other people. In all likelihood, the individual is not angry with others, but rather because the cerebro-vascular accident has disabled him or her in some way (Lee-Hood Ahmad et al., 2009).

\section{DEALING WITH WORRY}

After a cerebro-vascular accident, both the survivor and the family are often uneasy about being on their own at home. They have many apprehensions and anxieties about what the future holds.

They also fear that a cerebro-vascular accident might happen again. They worry that the survivor of the cerebro-vascular accident may be unable to accept the disabilities and they also have concerns that the caregiver may not be prepared to face the responsibility of caring for the survivor of cerebro-vascular accident.

- Accept the occurrence of the cerebro-vascular incident.

- Learn to accept the presence of a worried thought without having to take it seriously and without having to get rid of it (Neuman, 2003).

DEALING WITH GUILT

Gallozi (2008) states that it is not feeling guilty that is bad, but unresolved guilt that is harmful. However, Opp and Samson (2005) maintain that cognitive (thinking) and affective (feeling) components are at play in survivor guilt.

Take an asset or strength inventory. What qualities or strategies have helped you through times of stress or crisis before? Call upon those strengths. Remember that you were strong and resilient in your efforts to survive.

\subsubsection{Expected learning outcomes}

After this session the participants should be able to

- Deal with negative emotions: anger, worry and guilt.

\section{Conclusion}

This article has specified the purpose and objectives of the implementation of the programme. The process of implementing the supportive programme was outlined based on the schedule and facilitation of the training sessions. The dynamics focused on supportive educative guidance, and the following were described: reframing the knowledge and skills relating to self-care, modifying the daily routine, adjusting to altered social relationships as well as reframing negative emotions.

The participants were encouraged to apply what they have learnt from the training to their daily activities to enable them to master the situation, stabilising the change and functioning optimally at home.

\subsection{Content}




\section{Acknowledgement}

This article has been extracted from the author's study "An educational programme to support survivors of cerebro-vascular accidents and their caregivers at home" with the permission of the Ethical and Research Committee of the Namibian Ministry of Health and Social Services, the Oshana Regional Health Director and Oshana Regional Council's office. Special thanks are extended to the proof reader of this article.

\section{References}

[1] Armentrout, G. (2005). Community based nursing: Foundation for practice.Stamford,CT: Appleton \& Lange.

[2] Banning, M. (2005). Approaches to teaching: Current opinions and related research. Nurse Education Today, 25(7), 502-508. https://doi.org/10.1016/j.nedt.2005.03.007.

[3] Benner, P., \& Pratt, K. (2006). Dialogues with excellence: Extending the community of care. American Journal of Nursing, 91, 5859.

[4] Cookfair, J. M. (2004). Nursing care in the community (2nd ed.). St Louis, MO: Mosby.

[5] Gallozi, C. (2008). Coping with guilt. Retrieved from http://www.personaldevelopment.com/chuck/guilt.htm

[6] Hall, J. E., \& Weaver, B. R. (2004). A systems approach to community health (2nd ed.). Philadelphia, PA: JB Lippincott.

[7] Hartz, G. W., \& Splain, D. M. (2005). Psychosocial intervention in long-term care: An advanced guide. London: Haworth Press.

[8] Ignatavicius, D. D. (2003). Best practice: A guide to excellence in nursing care. Philadelphia, PA: Lippincott, Williams \& Wilkins.

[9] Kozier, B., Erb, G., Berman, A., \& Snyder, S. (2004). Fundamentals of nursing. California: Julie Levin Alexander.

[10] Lee-Hood Ahmad, E., Lennihan, L., Moore, S., Naylor, D., Tarvestad, D., \& Zorowitz, R. (2009). HOPE: The stroke recovery guide. USA: National Stroke Association.

[11] McEwen, M. (2004). Community-based nursing: An introduction. Philadephia, PA: WB Saunders.

[12] Myco, F. (2006). Nursing care of the hemiplegic stroke patient. London: Harper and Row.

[13] Neuman, F. (2003). Worried sick? The exaggerated fear of physical illness: How to put physical symptoms in perspective, how to avoid unnecessary worry. Retrieved from htpp://www.Anxiety and stress.com/dealing withworry.html

[14] Opp, R. E., \& Samson, A. Y. (2005). Taxonomy of guilt for combat veterans. Professional Psychology: Research and Practice, 20,159165. https://doi.org/10.1037/0735-7028.20.3.159.

[15] Peu, M. D. (2008). Home/community-based care. Pretoria: Van Schaik.

[16] Simmons-Mackie, N. N., \& Damico, J. S. (2004). Accounting for handicaps in aphasia: Communicative assessment from an authentic social perspective. Disability and Rehabilitation, 18, 540-549. https://doi.org/10.3109/09638289609166315. 